ISAHP Article: A Style Guide for Individual Papers To Be Submitted to the International Symposium of the Analytic Hierarchy Process 2018, Hong Kong, HK.

\title{
MULTICRITERIA ANALYSIS CONSIDERING UNCERTAINTY FOR THE SELECTION OF THE ELECTRIC POWER SUPPLY SYSTEM - POZO HONDO, PARAGUAYAN CHACO
}

\section{ABSTRACT}

This work proposes a solution to the lack of electricity supply to the city of Pozo Hondo, a community in the northern most part of the Paraguayan Chaco. A financial analysis is carried out for the proposal of a system that supplies Power to Pozo Hondo. Additionally, a multicriteria analysis was carried out, considering the following evaluation criteria: i) the cost of energy, ii) levels of greenhouse gas emissions, iii) feasibility of political decision. TPower demand projections for Pozo Hondo of the were based on historical data of communities with similar characteristics in the country. The supply alternatives considered were: thermal (diesel), renewable (wind and solar), and an extension of the distribution line $(23 \mathrm{kV})$. To find the best alternative, the the microgrid optimization platform HOMER Pro ${ }^{\circledR}$ was used. On the basis of the HOMER Pro results the Monte Carlo methodology is applied to introduce fluctuations in the price of diesel into the financial analysis in such a way as to contrast the alternatives of thermal (diesel) generation and renewable energy (wind and solar). Finally, the Analytic Hierarchy Process (AHP) is applied to obtain the most convenient alternative, considering multiple criteria. The research concludes that the optimal supply solution, considering multiple criteria would be that of a hybrid system (thermal and solar).

Keywords: Renewable Energy, Isolated Town, Cost of Energy, Monte Carlo, AHP

\section{Introduction}

Paraguay is a country with very particular characteristics in regard to its electrical system, which has a generation that is almost exclusively hydroelectric thanks to its Itaipu, Yacyretá and Acaray plants, with an installed capacity of 8,820 MW (Ríos, 2018). With these plants Paraguay has a surplus of electricity which is not consumed due to its small demand for national electricity, this represents a paradox, since in several areas of its territory they do not have a distribution network, which represents a percentage of its population does not have access to electricity.

The Administración Nacional de Electricidad (ANDE) is the Company in charge of the supply of electric power in Paraguay, with a coverage of the service at national level of $99.8 \%$, the remaining $0.2 \%$ is not currently served due to the technical and economic difficulties that this represents, particularly due to the low demand of these population centers and the long distances to the main generation centers. Paradoxically, the installed capacity in generation of $8,820 \mathrm{MW}$ and its national electricity demand is only around 3,300 MW. The town of Pozo Hondo is not exempt from this problem of isolation of the National Interconnected System (NIS) as shown in Figure 1. The town is located in the western region of Paraguay, on the left bank of the Pilcomayo River, just northwest of the department of Boquerón, Paraguayan Chaco and is currently without a continuous power supply.

\section{Literature Review}

During the visit to the city in September 2017, it was noted that the Pozo Hondo Town is an isolated locality of the National Interconnected System, where, currently, through a communal self-management, a thermal generator of $36 \mathrm{~kW}$ is available for electricity supply from 4 to 6 hours per day. The main loads connected to this generator correspond 
ISAHP Article: A Style Guide for Paper Proposals To Be Submitted to the International Symposium on the Analytic Hierarchy Process 2018, Hong Kong, HK.

to: i) public lighting system, ii) some homes, and iii) public institutions. The distribution of electrical energy is carried out by means of a three-phase low voltage network (length of approximately $1 \mathrm{~km}$ ) that crosses the town's hull. In the same way, it was found that, in terms of obtaining and distributing drinking water, it is carried out by means of a motor pump powered by solar panels in the municipal office. It was also observed that some houses had solar panels and diesel thermal generation of small size for their own consumption.

Reflecting on the availability of the energy resources that nature offers to this town, this contribution focuses on analyzing: i) the possibility of on-site generation of renewable energy and thermal generation and ii) additionally on the feasibility of interconnection to the nearest electrical network ( $23 \mathrm{kV}$ distribution line).

An important aspect that this project considers is the fact that according to the current Schedule of Tariff No. 21 (ANDE, 2017) of the ANDE establishes that all cargo handled must comply with the current national residential rate that is 365 PYG per kWh $(0.066$ USD per kWh) unlike the previous statement No. 20 with which it could discriminate the Chaco electrification projects by establishing a differentiated tariff (which was never applied). By virtue of the aforementioned, in the study of electric power generation alternatives, which a priori would present a higher generation cost compared to the ANDE Rate, it is considered that this work should include state support and financing for the implementation of a generation of electrical energy of reliability and continuity. In this project the following generation sources were considered: i) thermal with diesel, ii) wind, iv) solar photovoltaic, and v) an optimal mix of the previous ones.

Figure 2 (Ríos \& Ferreira, 2014) shows an average cost in USD / $\mathrm{kWh}$ of electric energy for the Chaco of the possible alternative systems considered in comparison with the residential tariff of the ANDE.

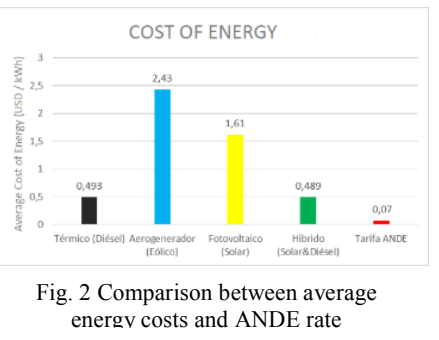

\section{Data/Model Analysis: Development of the stages of the research}

The project was divided into two stages: i) the first stage, which was based on identifying the electric situation of the population and recognizing the potential conditions in renewable energy in the area; and ii) evaluating and prospecting primary energy resources, and infrastructure available to carry out a power supply in the city of Pozo Hondo.

Stage 1: Consumption profile and projection of electricity demand

The first step of this work was to characterize the possible demand of electric power of the population with a continuous supply of 24 hours a day, based on data obtained and discussed with authorities of the ANDE, the possible curve of daily electricity demand of the locality could be compared with the consumption of the city of Bahía Negra (Ríos \& Ferreira, 2014), being that this for the city of Pozo Hondo locality presents several socioeconomic similarities with the town of Pozo Hondo, such as, for example, being a rural Chaco border town that also has activities economic fishing, hunting, jobs in livestock and a commercial exchange of comparable similarities. Taking into account these factors, it is possible to extrapolate the demand curve of Bahía Negra and consider that the load in Pozo Hondo would have a similar behavior. In fig. 4 represents the estimate of electricity demand in Pozo Hondo with a peak of $25 \mathrm{~kW}$. 
ISAHP Article: A Style Guide for Paper Proposals To Be Submitted to the International Symposium on the Analytic Hierarchy Process 2018, Hong Kong, HK.

In the projection of the electricity demand, for this case study, the concept of repressed demand was considered, where an interannual growth of $30 \%$ was estimated during the first two years, and of $10 \%$ for the following years of the project horizon.

The hypothesis could be considered validated after the survey that was conducted in the city to estimate what would be the average consumption of the inhabitants in the future, reaching $83.1 \mathrm{~kW}$ of estimated demand for the last year, very close to the value obtained through the projected growth

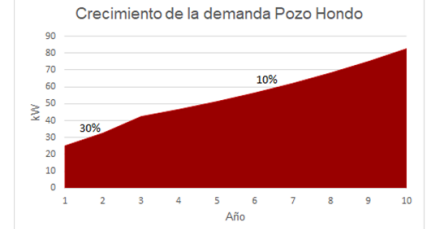

Fig. 4 Projection of demand growth for 10 years rates.

Stage 2: Prospecting for possible supplies of electric power

This stage consisted in prospecting the possible ways of supplying electricity to the city, taking into account first which of them were more feasible to apply, recognizing the available technologies and an important factor called economy of scale, which defines that, although a system It is cheaper than another, it can only be considered from a certain level of demand (Andrade, 2017).

The cost of extending a $23 \mathrm{kV}$ line that is around USD 16,000 per $\mathrm{km}$ was estimated. To carry out this interconnection, an extension of approximately $100 \mathrm{~km}$ is required. The ends of the line where this extension would fit come from feeders of the Mariscal Estigarribia substation, located in the city with the same name, $220 \mathrm{~km}$ from the city of Pozo Hondo. The investment for the extension would be USD 1,600,000. Considerations such as the quality and reliability of the service, would be compromised because of the great distances involved. Even so, it is taken as an alternative since it is a method used to mitigate the lack of electric power in the Paraguayan Chaco region.

The utilization of the energy potential of the Pilcomayo River as a source of energy for the generation was analyzed in a preliminary way, an option that was quickly ruled out, since this water caduceus suffers in very high intensity (the second largest in the world) in a large part of this section of a hydrological phenomenon known as siltation (Grosso, 2016), which becomes very variable to the conditions of the river necessary for its use. In addition, the flow of this river allows the arrival of water to the Paraguayan and Argentinean Chaco, so that damming affects human and wild life in these places to a great extent (González \& González, 2013).

In turn, the potential of solar radiation for the installation of photovoltaic panels was studied, finding that the conditions of the area are suitable for exploitation. The analysis of the existing wind potential in the area was also taken into account, being the area with the greatest wind potential in the country, so this technology becomes interesting in its analysis for the generation of electric power.

Finally, the use of diesel generation was considered as the sole source of generation, as incorporated into a hybrid generation system in conjunction with a renewable and clean energy resource such as solar, which was also studied independently.

\section{Materials and methods}

The project contemplated the use of the following tools for the search of the most suitable generation system as well as the optimization of the scenario in probabilistic terms. In turn, a multicriteria decision model to determine the best alternative considering financial, production cost, environmental and political criteria.

Software HOMER Pro: By means of the simulation of the generation systems with the HOMER software (Hybrid Optimization Model for Multiple Energy Resources), the lowest cost system was determined that meets the minimum technical needs that a generating plant must satisfy. The program can simulate isolated systems with both conventional and renewable energy sources, making the arrangement of generating machines more convenient, taking the economic parameter as the main decision axis. 
ISAHP Article: A Style Guide for Paper Proposals To Be Submitted to the International Symposium on the Analytic Hierarchy Process 2018, Hong Kong, HK.

It is important to emphasize that this software is an optimization tool and not modeling, so it is a fundamental requirement to manually design the first electric power supply systems and then proceed to obtain the best versions. The starting point in the simulation is the determination of the load.

Monte Carlo method: The application of this method was to find the expected value of the diesel price over the time of the project to have the finest possible results, for the case of systems dependent on this hydrocarbon. In Table 1 we can observe the values obtained by the simulations.

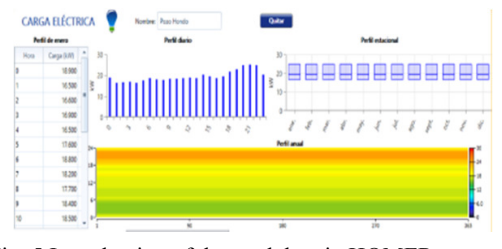

Fig. 5 Introduction of demand data in HOMER

Analytic Hierarchy Process $(A H P)$ : The AHP was used in this work to evaluate the best configurations of electricity supply based on multiple criteria.

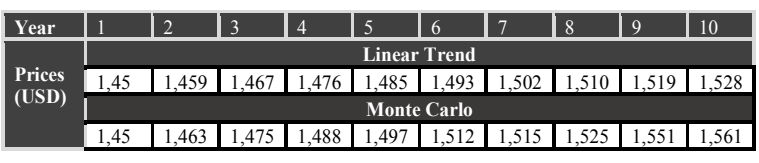

Table 1: Expected values of the diesel price vs linear trend

For the financial criterion, the Net Present Value (NPV) of each configuration was taken as an indicator. As an indicator for the cost of production criterion, the Standardized Cost of Energy (COE) was taken. Regarding the quantifier of the environmental criterion, it was decided to include the Greenhouse Effect Gas Emissions (GEGE) of the systems. And for the political criterion, the experience of the decision makers was taken as an indicator, which could be obtained thanks to the creation of a panel of experts in the planning area of the ANDE, the Vice Ministry of Mines and Energy, and the Research Group of Energy Systems. The criteria were also weighted by the panel of experts.

The alternatives were a purely diesel configuration, a solar photovoltaic, a wind, a hybrid (Solar \& Diesel) and a line extension of $23 \mathrm{kV}$.

Finally, a sensitivity analysis of the criteria (Figure 7) was carried out to compare its results with the evaluation criteria of the expert panel.

In Figure 6 we can see the decision tree corresponding to this analysis.

\section{Results \& Conclusions}

Multi-criteria decision making:
Considering the decision-making methodology (AHP) used to determine the best alternative: According to the priority given by the experts to the criteria and a sensitivity analysis made to the weighting of the criteria, when making the pertinent comparisons between matrices, the final priority is the best alternative to the Hybrid configuration (Solar \& Diesel).

Specifications of the best configuration:

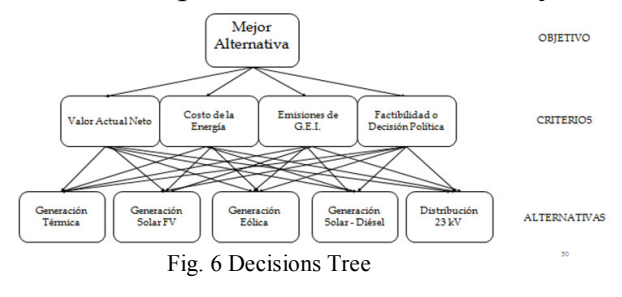

The winning configuration coast of two diesel thermal generators of $48 \mathrm{~kW}$ and $80 \mathrm{~kW}$ of power in continuous regime each one. An array of $65 \mathrm{kWp}$ photovoltaic cells, a $55-\mathrm{kW}$ inverter / inverter system and a 118-kWh battery bank of useful energy. In addition to the electrical systems mentioned, this includes a fuel tank of 20,000 liters.

Considering the two decision-making scenarios (expert preference and sensitivity analysis), the Hybrid system as the winner can be classified as the most preferred alternative, and the best option to be executed. 
ISAHP Article: A Style Guide for Paper Proposals To Be Submitted to the International Symposium on the Analytic Hierarchy Process 2018, Hong Kong, HK.

In order to propose a supply system, the first task is to characterize the load, for which it is vital to carry out surveys in order to estimate the behavior of the same and how to serve it. To have better established qualitative parameters, carrying out an expert panel consultation proved crucial as it allowed us to capture their valuations in a quantitative average according to their experience.

Finally, according to the proposed objectives, it can be said that the possible technically and economically feasible alternatives for electricity supply in the community of Pozo Hondo were analyzed considering an analysis of multiple criteria. Projecting a consumption profile to the community and analyzing the different alternatives for the supply of electrical energy, it was possible to present a supply of electric power of greater convenience considering economic, environmental and political feasibility criteria.

\section{Key References}

ANDE. (2017, junio 21). Pliego Tarifario $N^{\circ}$ 21. Retrieved from http://www.ande.gov.py/docs/tarifas/PLIEGO21.pdf

Andrade, D. (2017, Junio 27). FALTA TITULO Pontificia Universidad Católica del Ecuador. Retrieved from http://www.puce.edu.ec/

Estudios Energéticos Consultores. (2015). Asistencia Técnica para la Elaboración de los Estudios de Costos y Tarifas, Caracterización y Estudios de la Demanda de la Energía Eléctrica y formulación de Escenarios Económicos - Resumen Ejecutivo. Asunción.

González, R., \& González, U. (2013, Agosto 28). FALTA TITULO ABC Color. Retrieved from http://www.abc.com.py

Grosso, T. (2016, Junio 27). La Bioguía. Retrieved from http://www.labioguia.com/

Ríos, R., \& Ferreira, E. (2014). Anlisis y Optimizacioón de recursos energéticos de la ciudad de Bahia Negra Chaco Paraguayo. San Lorenzo: Facultad Politécnia de la Universidad Nacional de Asunción.

Ríos, R. (2018). Análisis de opciones de comercialización de energía eléctrica paraguaya de itaipú binacional en el mercado eléctrico brasilero. San Lorenzo: Facultad Politécnica de la Universidad Nacional de Asunción Paraguay. 